\title{
Gender differences in lying in sender-receiver games: A meta-analysis
}

\author{
Valerio Capraro*
}

\begin{abstract}
Whether there are gender differences in lying has been largely debated in the past decade. Previous studies found mixed results. To shed light on this topic, here I report a meta-analysis of 8,728 distinct observations, collected in 65 Sender-Receiver game treatments, by 14 research groups. Following previous work and theoretical considerations, I distinguish three types of lies: black lies, which benefit the liar at a cost for another person; altruistic white lies, which benefit another person at a cost for the liar; and Pareto white lies, which benefit both the liar and another person. The results show that: males are significantly more likely than females to tell black lies $(\mathrm{N}=4,173)$; males are significantly more likely than females to tell altruistic white $(\mathrm{N}=2,940)$; and results are inconclusive in the case of Pareto white lies $(\mathrm{N}=1,615)$. Furthermore, gender differences in telling altruistic white lies are significantly stronger than in the other two cases.
\end{abstract}

Keywords: lying, honesty, deception, gender differences, sex differences.

\section{Introduction}

Many economic and social interactions are characterized by asymmetric information. In these situations, people may be tempted to misreport their private information. Although standard economic theory predicts that people would lie as long as that is beneficial to themselves, empirical research in economics and psychology has shown that people do not always lie. Cases in which people act honestly abound, even when being dishonest would be beneficial to all parties involved (Erat \& Gneezy, 2012; Cappelen, Sørensen \& Tungodded, 2013; Biziou-van-Pol, Haenen, Novaro, OcchipintiLiberman \& Capraro, 2015).

Why do some people act honestly while others do not?

Previous studies have approached this question from several angles. For example, scholars have explored the role of social and moral preferences (Biziou-van-Pol et al, 2015; Levine \& Schweitzer, 2014; Levine \& Schweitzer, 2015; Shalvi \& de Dreu, 2014; Weisel \& Shalvi, 2015), the role of incentives (Dreber \& Johannesson, 2008; Erat \& Gneezy, 2012; Fischbacher \& Föllmi-Heusi, 2013; Gneezy, 2005; Gneezy, Kajackaite \& Sobel, 2018; Mazar, Amir \& Ariely, 2008; Sutter, 2009), the role of group-serving lies versus individual-serving lies (Cohen, Gunia, Kim-Jun \& Murnighan, 2009; Conrads, Irlenbusch, Rilke \& Walkowitz, 2013; Gino, Ayal \& Ariely, 2013; Wiltermuth, 2011), and the role of manipulating cognitive resources (Gino, Schweitzer, Mead \& Ariely, 2011; Shalvi, Eldar \& Bereby-Meyer, 2012; Gunia et al., 2012; van't Veer, Stel \& van Beest, 2014; Capraro, 2017; Barcelo \& Capraro, 2017; Lohse, Simon \& Konrad, 2018).

Copyright: (C) 2018. The authors license this article under the terms of the Creative Commons Attribution 3.0 License.

*Middlesex University, London, UK. Email: V.Capraro@mdx.ac.uk.
Another line of research that has received a great deal of attention is whether there are gender differences in lying. An early paper by Dreber and Johannesson (2008) found that males lie more than females, at least in the domain of black lies, that is, lies that benefit the liar at a cost for another person. This result was successfully replicated in some studies (Friesen \& Gangadharan, 2012; Capraro, Schulz \& Rand, 2018) but not in others (Childs, 2012; Capraro \& Peltola, 2018), which found no gender differences in the context of black lies. Subsequently, Erat and Gneezy (2012) observed that the sign of gender differences in lying might depend on the consequences of the lie: they found that males lie more than females in the context of Pareto white lies (lies that benefit both the liar and another person), but females lie more than males in the context of altruistic white lies (lies that benefit another person at a cost for the liar). However, the former result was not replicated by Cappelen et al. (2013), who found no gender differences in the context of Pareto white lies; and the latter result was not replicated by Biziou-van-Pol et al (2015), who, in fact, found the opposite, that males tell more altruistic white lies than females. These mixed results suggest that gender differences in lying, if they exist, might be small and dependent on the consequences of lying. Thus a meta-analytic approach can be useful to shed light on the topic.

The contribution of this work is to make a step in this direction by analyzing a large sample of more than 8,500 observations, coming from 65 different treatment conditions, conducted by 14 different research groups, by taking also into account the consequences of lying. 


\subsection{Measure of honesty}

Researchers have developed several measures of honest behavior. For example, in Fischbacher and Föllmi-Heusi (2013), participants roll a die, in private, and then report the resulting outcome knowing that they will be paid an amount equal to the number they report, unless the number is six, in which case they do not get any payment. Thus participants have an incentive to lie (unless they get a five) for their benefit. See also Greene \& Paxton (2009), Fosgaard, Hansen \& Piovesan (2013), Ploner \& Regner, (2013), Shalvi \& Leiser (2013), Pascual-Ezama, Prelec \& Dunfield (2013), van't Veer, Stel \& van Beest (2014). Conceptually similar is the matrix search task (Mazar, Amir \& Ariely, 2008) and the visual perception task (Gino, Norton \& Ariely, 2010). The common denominator of these paradigms is that participants complete a task and then they are paid according to the selfreported performance in this task. Thus, also in this case, participants are incentivized to lie for their own benefit.

Conceptually different is the so-called Sender-Receiver game (also known as Deception game). There are various formulations of this game (Gneezy, 2005; Erat \& Gneezy, 2012), differing in relatively minor details of the strategy space or the type of information provided. But the general structure is as follows. The experimenter gives a piece of information (for example, the outcome of a die) to Player 1, but not to Player 2. Then Player 1 is asked to report this information to Player 2. The role of Player 2 is to guess the original piece of information (for example, the true outcome of the die). If Player 2 guesses the original piece of information, then Player 1 and Player 2 get paid according to Option A; if Player 2 does not guess the original piece of information, then Player 1 and Player 2 get paid according to Option B. Only Player 1 knows the exact allocations of money corresponding to Option A and Option B. One variant of the deception game was introduced by Biziou-van-Pol et al. (2015), in order to avoid the problem of sophisticated deception (i.e., Player 1 telling the truth because he or she expects that Player 2 will not believe him or her, Sutter 2009). In this variant, Player 2 has no active choice: whether participants are paid according to Option A or Option B depends only on whether Player 1 decides to lie or to tell the truth.

The Sender-Receiver game is particularly interesting because it allows to distinguish four types of lies, depending on the payoffs associated to Option A and Option B. Employing the terminology introduced by Erat and Gneezy (2012), I use the following taxonomy: black lies are those that benefit the liar at the expenses of the other person; altruistic white lies are those that benefit another person at a cost for the liar; Pareto white lies are those that benefit both the liar and the other person; Spiteful lies are those that harm both the liar and the other person. The goal of this work is to study gen- der differences on lying as a function of the consequences of lying.

\subsection{Theoretical considerations}

As mentioned above, previous empirical work suggests that the sign of gender differences in lying may depend on the consequences of the lie. The existence of such a dependence is in fact expected and can be actually derived from considerations regarding gender differences in social preferences and moral judgments.

Previous work shows that males are more selfish than females in the dictator game, at least among students and Mechanical Turkers (Croson \& Gneezy, 2009; Branas-Garza, Capraro \& Rascón-Ramírez, 2018; Rand et al, 2016), although perhaps not in the general population (Carpenter, Connolly \& Myers, 2008; Cappelen, Nygaard, Sørensen \& Tungodden, 2015). Several studies have also provided evidence that males donate less than females to charity (De Wit \& Bekkers, 2016; Mesch et al, 2006; Piper \& Schnepf, 2008). In line with this view, social role theorists argue that males are more agentic and independent, while females are more unselfish and communal (Eagly, 1987). These observations suggest that self-regarding motivations may push males to tell more black lies than females, even when their intrinsic costs of lying are, on average, the same.

Regarding gender differences in altruistic behavior, Andreoni and Vesterlund (2001) found that females are more altruistic than males when the altruistic action coincides with the egalitarian action, but males are more altruistic than females when the altruistic action is socially efficient. This suggests that gender differences in the decision to tell altruistic white lies may depend on the actual consequences of lying, such that females may tell more altruistic lies than males when lying minimizes payoff differences, while males may tell more altruistic white lies than females when lying is socially efficient.

Regarding Pareto white lies, two different arguments lead to the prediction that it is likely that there are no major gender differences in lying. On the one hand, Pareto white lies - at least those studied in previous literature and reported in this paper - are both socially efficient and egalitarian. Thus, the Andreoni and Vesterlund's (2001) result mentioned above suggests that females and males might be equally motivated to tell Pareto white lies. An alternative argument descends from considerations about the morality of lying. According to deontological ethics, an action is morally good if it instantiates certain rules or ethical norms, regardless of the consequences, and is morally bad if it violates them. Telling the truth when lying is beneficial to all parties involved is thus a typically deontological choice, as it corresponds to following the rule "don't lie", regardless of consequences. Therefore, the question whether there are gender differences in telling Pareto white lies can be seen as a particular spec- 
ification of the more general question of whether there are gender differences in deontological moral judgments. Previous research suggests that females are more deontological than males, but only in moral dilemmas that involve directly harming others for the greater good (Capraro \& Sippel, 2017; Fumagalli et al, 2010; Friesdorf et al, 2015). Since lying in a Pareto white lie condition does not involve direct harm to others, also this argument suggests that it is likely that there are no major gender differences in telling Pareto white lies.

\section{Data collection}

Data collection proceeded in several steps. First, on April 1, 2016, I announced my plan of conducting a meta-analysis of two-player sender-receiver games on the ESA Experimental Methods Discussion Google Group. In this way, scholars interested in having their work included in the meta-analysis could send me the raw data of their experiment(s). In the days after, I have also conducted a $2 \times 4$ google scholar search looking for pairs of keywords of the shape [gender, sex] $\mathrm{x}$ [honesty, dishonesty, lying, deception], and I emailed the authors of all relevant papers and requested the raw data of their experiment(s). In doing so, I received raw data of 18 different experimental treatments (some published, some not), to which I have added 32 different experimental conditions of my research group (some published, some not). To minimize file-drawer effects, I included in the meta-analysis also unpublished studies. Then I wrote a first draft of the meta-analysis (6,508 observations), which I posted on SSRN on March 11, 2017. I left this first draft online for almost one year. Then, on January 25, 2018, I emailed the ESA Experimental Methods Discussion Google Group again, announcing my plan to revise the meta-analysis. In this occasion, scholars whose work had not been included in the first version of the meta-analysis could send me the raw data of their experiment(s). I sent the same email also to the Society for Judgment and Decision Making emailing list, and I made again the same $2 \times 4$ google search that I had made before. In this second version of the meta-analysis ${ }^{1}$, I thus analyze a total of 65 experimental treatments (36 from my own research group and 29 from 13 different research groups), for a total of 8,728 distinct observations (4,173 in black lies conditions, 2,940 in altruistic white lies conditions, 1,615 in Pareto white lies condition, and 0 in spiteful lies conditions). Distinct means that, in case a subject participated in more than one study (some studies were conducted on Amazon Mechanical Turk, so I could keep track of subjects using their MTurk ID and their IP address), I keep only the first observation. Similarly, in case the data come from iterated games, I keep only the first observation.

\footnotetext{
${ }^{1}$ After receiving the comments from the referees and while preparing the revision, I have emailed the ESA Experimental Methods Discussion Group and the Society for Judgment and Decision Making emailing list again to collect more data. However, I did not receive any more data this time.
}

\section{Overall analysis}

I start analyzing all 65 studies together. To do so, for each single study, I use logit regression to compute the effect of gender on honesty (which is a binary variable) with and without control on age and level of education (when known). ${ }^{2}$ Logit regression applied to single studies has the limitation that, if the dependent variable can be perfectly predicted, it returns no coefficient. For example, if, for a given study, all females act honestly, then logit regression returns no coefficient. This happens rarely in these dataset (3 studies over 65). When this happens, I do a correction by adding one data point by hand in such a way to maintain the sign of the effect.

Then I build a .csv file with twenty columns: study, genderc, genderse, genderc_control, genderse_control, altruistic_lie, black_lie, pareto_lie, capraro, levine, greenberg, kouchaki, rode, cohen, gneezy, hershfield, roeser, dreber, gunia, shemereta, where, for each study, genderc (resp. genderse) is the coefficient (resp. the standard error) of the logit regression predicting honesty as a function of gender without control on age and level of education; similarly, genderc_control(resp.genderse_control) is the coefficient (resp. the standard error) of the logit regression predicting honesty as a function of gender with control on age and level of education; altruistic_lie, black_lie, and pareto_lie are three dummy variables that represent the consequences of lying in the corresponding sender-receiver game ${ }^{3}$; and capraro, levine, greenberg, kouchaki, rode, cohen, gneezy, hershfield, roeser, dreber, gunia, shemereta are dummy variables representing the research group of the corresponding study, which I include as a potential moderator.

To look at the effect of gender on lying, I conduct randomeffect meta-analysis with the Stata command: metan genderc genderse, random label(namevar=study). The results, shown in Figure 1, clearly show a significant overall effect such that females are more honest than males (effect size $=$ $0.271,95 \% \mathrm{CI}=[0.172,0.370], \mathrm{Z}=5.37, \mathrm{p}<0.001)$. This effect is robust after controlling for age and level of education (effect size $=0.283,95 \% \mathrm{CI}=[0.182,0.384], \mathrm{Z}=5.49, \mathrm{p}<$ 0.001 ). Furthermore, there is no evidence of heterogeneity across studies in the true size of this effect (without control: $\mathrm{p}=0.553$; with control: $\mathrm{p}=0.631$ ).

To test for potential publication bias and small study effect, without and with control on age and education, I conduct Egger's test and Begg's test with the Stata commands metabias

${ }^{2}$ I include controls for age and education because they seem to have an effect on lying (logit regression over the pool of studies; age: coeff $=$ $0.005, \mathrm{z}=2.40, \mathrm{p}=0.016$; education: coeff $=-0.081, \mathrm{z}=-3.90, \mathrm{p}<.001)$. Moreover, age has a significant effect on gender (coeff $=0.116, z=5.94, p$ $<.001)$, while education has no correlation with gender $($ coeff $=-0.019, \mathrm{z}$ $=-0.92, \mathrm{p}=0.357)$.

${ }^{3}$ I do not include a dummy variable to represent the actual consequences of lying in the case of altruistic white lies (socially efficient vs. egalitarian) because in all studies analyzed in this work lying in the altruistic white lie conditions is always socially efficient. 


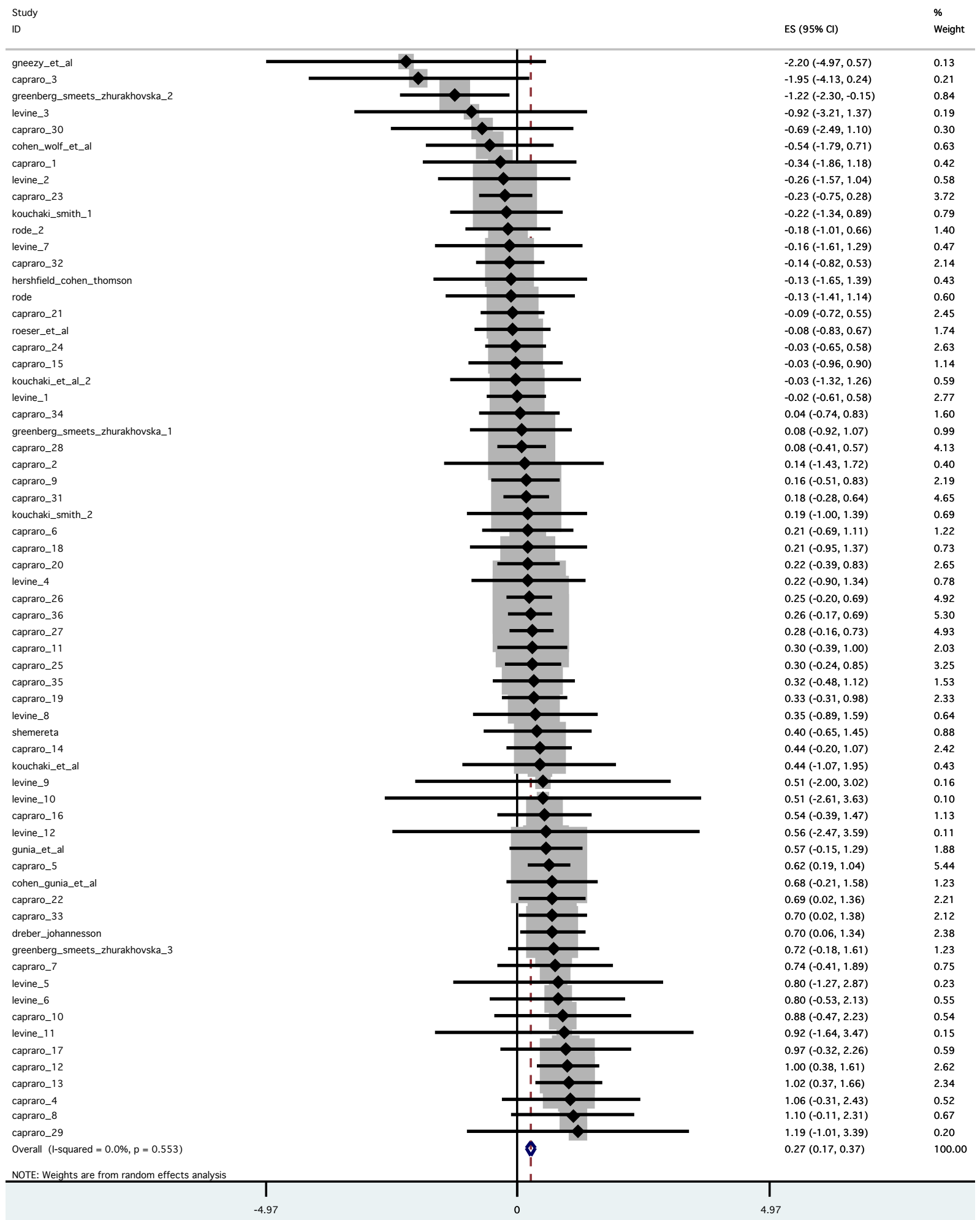

FIGURE 1: Meta-analysis of gender differences on lying across all 65 studies (with no control on age and level of education). 
genderc genderse, egger, metabias genderc_control genderse_control, egger metabias genderc genderse, begg and metabias genderc_control genderse_control,begg. In doing so, I find no evidence of publication bias and small study effect (Egger's test: without control: $t=-0.99, p=0.328$; with control: $\mathrm{t}=-0.67, \mathrm{p}=0.507$; Begg's test: without control: $\mathrm{z}=-0.62, \mathrm{p}=0.533$; with control: $\mathrm{z}=-0.44, \mathrm{p}=$ $0.659)$.

Next, I explore whether the gender effect depends on lie type. To do so, I conduct meta-regression with the Stata command metareg genderc altruistic_lie black_lie, wsse(genderse) and then I test whether the gender effect depends on the categorical variable of lie type by launching the command test altruistic_lie black_lie. In doing so, I find a significant effect $(p=0.049)$ of lie type, suggesting that, indeed, gender differences in lying depends on the consequences of the lie. The mean effect sizes for the three lie types are .19 for black lies, .47 for altruistic white lies, and .22 for Pareto white lies.

A potential problem with this analysis is that some studies come from the same research group. Controlling for research group by launching the command metareg genderc altruistic_lie black_lie capraro levine greenberg kouchaki rode cohen, wsse(genderse), I find that the effect of lie type is robust $(\mathrm{p}=0.035)$.

To better understand the moderation effect of lie type, I analyzed the gender effect as a function of two dummy variables, one for altruistic white lies and one for black lies, using Pareto white lies as the baseline, and again controlling for research group. ${ }^{4}$ Although the difference between Pareto lies and black lies was clearly not significant, consistent with the similarity of the two effect sizes, the difference between Pareto lies and altruistic white lies was significant (without control: $p=.045$; with control: $p=.032$ ), a result that is also consistent with the effect size difference, although weak because of the small number of studies of Pareto lies. A similar analysis showed a highly significant difference in the gender effect between black lies and altruistic white lies. In sum, once again, the gender effect appears to be greater in altruistic white lies than in the other two types.

In the next sections, I analyze the gender effect on lying for each of these conditions more closely.

\section{Black lies}

I start by analyzing gender differences on the decision to tell black lies, i.e., lies that benefit the liar at the expenses of another person.

${ }^{4}$ This analysis was done with the metafor package of $\mathrm{R}$, which otherwise produced results identical to those reported in this article, except for an occasional difference in the last decimal place. Research group itself had an almost-significant effect $(\mathrm{p}=.093)$ when lie type was included, so it seemed necessary to keep it in the model.

\subsection{Dataset}

I analyze $\mathrm{N}=4,173$ distinct observations, coming from 36 different experimental conditions: fourteen conducted by my research group, six by Emma Levine (unpublished), one by Sheremeta \& Shields (2013), three by Greenberg, Smeets, and Zhurakhovska (2015), one by Dreber and Johannesson (2008), one by Cohen, Gunia, Kim-Jun and Murnighan (2009), one by Cohen, Wolf, Panter and Insko (2011), one by Gneezy et al (2013), one by Gunia et al (2012), one by Hershfield, Cohen and Thomson (2012), two by Kouchaki and Smith (2014), two by Kouchaki, Smith-Crowe, Brief and Sousa (2013), two by Rode (2010), and one by Roeser et al (2016).

\subsection{Analysis}

On average, $36 \%$ of males versus $44 \%$ of females are honest. Random-effects meta-analysis shows that females are significantly more honest than males (effect size $=0.186$, $95 \% \mathrm{CI}=[0.053,0.319], \mathrm{Z}=2.73, \mathrm{p}=0.006)$. This effect is robust after controlling for age and, when possible, for level of education (effect size $=0.184,95 \% \mathrm{CI}=[0.049,0.320]$, $\mathrm{Z}=2.67, \mathrm{p}=0.008$ ). Furthermore, there is no evidence of heterogeneity across studies in the true size of this effect (without control: $p=0.787$; with control: $p=0.836$ ). Figure 2 is a forest plot of the meta-analysis. Finally, Egger's test (without control: $\mathrm{z}=-0.56, \mathrm{p}=0.580$; with control: $\mathrm{z}=0.15, \mathrm{p}=0.878$ ) and Begg's test (without control: $\mathrm{z}=$ $-0.58, \mathrm{p}=0.565$; with control: $\mathrm{z}=-0.05, \mathrm{p}=0.958$ ) show no evidence of publication bias and small study effect.

Note that the overall effect is relatively small, and this might explain why previous research failed to consistently detect gender differences. A power analysis indeed shows that, to detect the overall effect with power 0.9 at a $5 \%$ significant level, one needs a sample of size $\mathrm{N}=3,091$.

\section{Altruistic white lies}

Next I analyze gender differences on the decision to tell altruistic white lies, lies that benefit another person at a cost for the liar.

\subsection{Dataset}

I analyze $\mathrm{N}=2,940$ distinct observations, in 20 experimental conditions: fourteen by my research group, and six (unpublished) by Emma Levine's. In all these conditions, lying is socially efficient, whereas telling the truth minimizes payoff differences. 


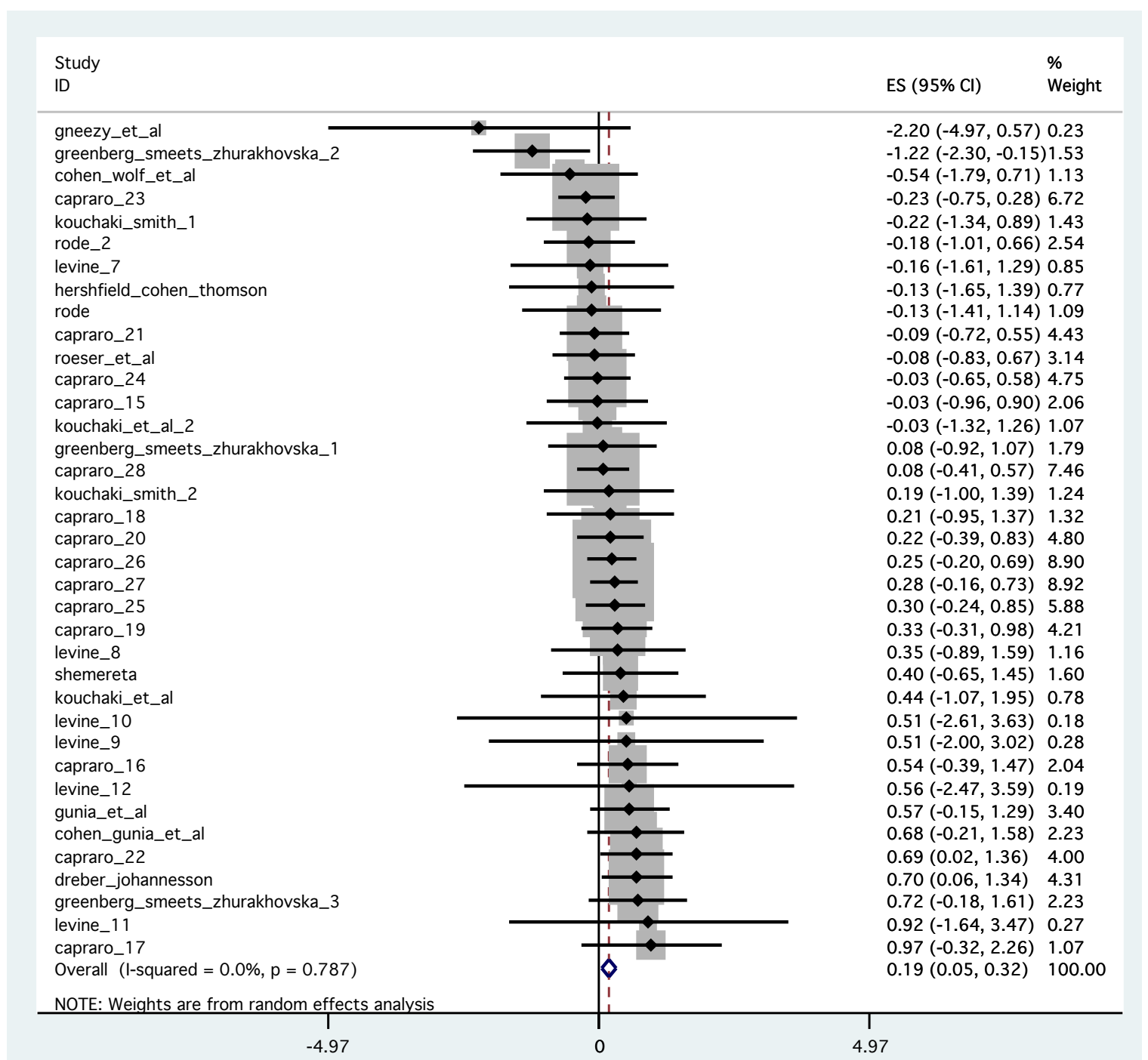

FIGURE 2: Forest plot of the meta-analysis of the gender differences in telling black lies (with no control on age and level of education).

\subsection{Analysis}

On average, $76 \%$ of males versus $83 \%$ of females acts honestly. Random-effects meta-analysis finds that females are more honest than males (effect size $=0.469,95 \% \mathrm{CI}=$ $[0.256,0.681], \mathrm{Z}=4.33, \mathrm{p}<0.001)$. This effect is also robust after controlling for sex and, when possible, for the level of education (effect size $=0.537,95 \% \mathrm{CI}=[0.341,0.733]$, $\mathrm{Z}=5.37, \mathrm{p}<0.001)$. Furthermore, there is no evidence of heterogeneity across studies in the true size of this effect (without control: $p=0.315$; with control: $p=0.493$ ). Figure 2 shows a forest plot. Finally, there is no evidence of publication bias and small studies effect (without control: Egger's test: $\mathrm{t}=-0.70, \mathrm{p}=0.494$; Begg's test: $\mathrm{z}=-0.59, \mathrm{p}=0.552$. With control: Egger's test: $t=-0.94, p=0.359$; Begg's test:

$$
\mathrm{z}=-1.36, \mathrm{p}=0.172) \text {. }
$$

Note again that the overall effect is relatively small, and this might explain why previous research failed to consistently detect gender differences. A power analysis indeed shows that to detect the overall effect with power 0.9 at a $5 \%$ significant level one needs a sample of size $\mathrm{N}=728$.

\section{Pareto white lies}

Finally, I explore gender differences on the decision to tell Pareto white lies, that is, lies that benefit both the liar and another person. 


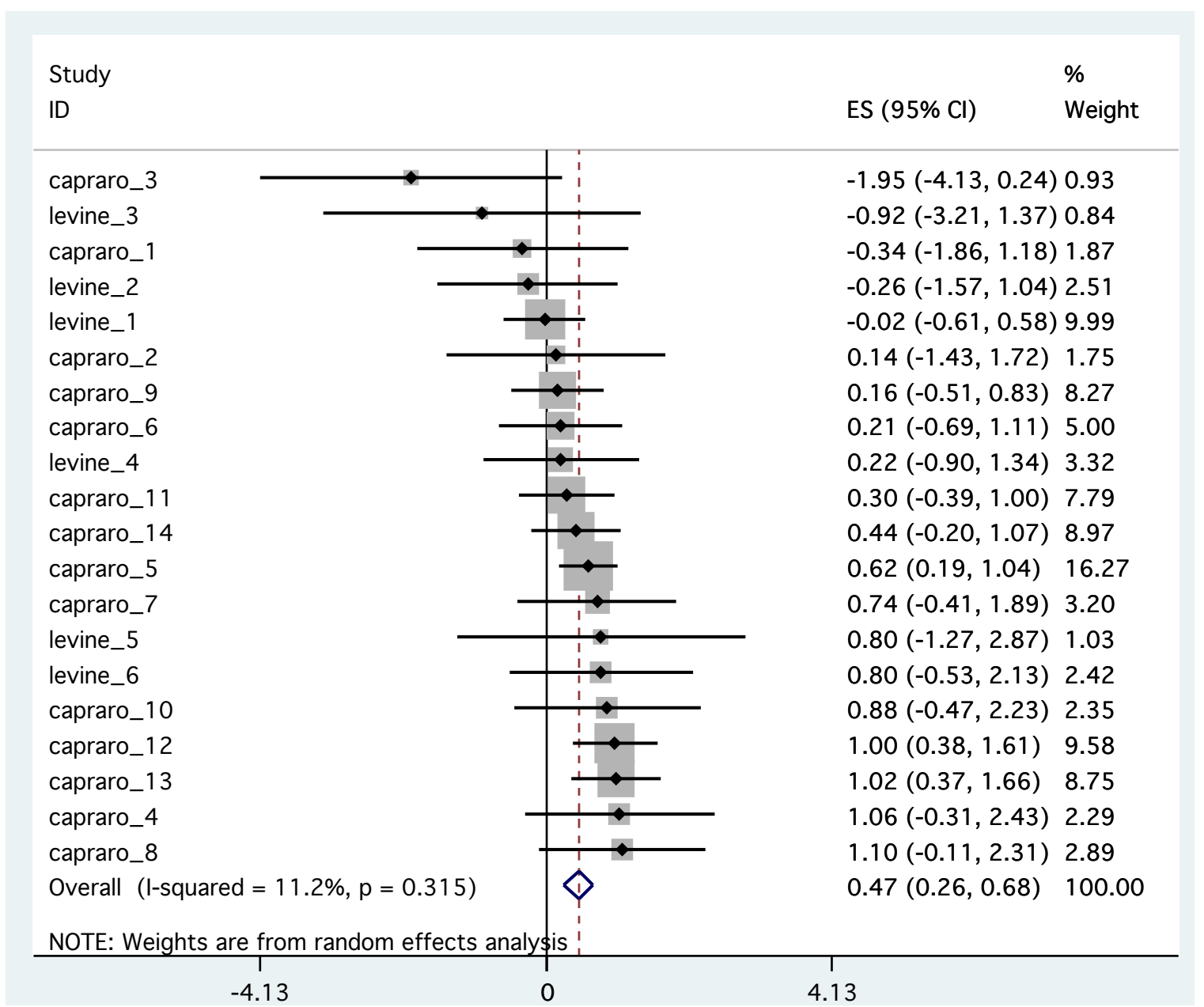

FIGURE 3: Forest plot of the meta-analysis of the gender differences in telling Altruistic white lies (with no control on age and level of education).

\subsection{Dataset}

I analyze $\mathrm{N}=1,615$ distinct observations, in 8 experimental conditions, all by my research group.

\subsection{Analysis}

On average, $26 \%$ of males versus $29 \%$ of females acts honestly. Random-effect meta-analysis finds that males are almost significantly more dishonest than females, when I do not control for age and level of education (effect size $=0.222$, $95 \% \mathrm{CI}=[-0.012,0.457], \mathrm{Z}=1.86, \mathrm{p}=0.063)$. However, this almost significant effect is a little weaker after controlling for age and level of education (effect size $=0.214,95 \%$ $\mathrm{CI}=[-0.026,0.455], \mathrm{Z}=1.75, \mathrm{p}=0.080)$. There is no heterogeneity across studies (without control: $p=0.654$; with control: 0.705 ) and no evidence of publication bias, neither without control (Egger's test: $t=-0.04, p=0.966$; Begg's test: $\mathrm{z}=0.25, \mathrm{p}=0.805)$, nor with control on age and education (Egger's test: $\mathrm{t}=0.13, \mathrm{p}=0.898$; Begg's test: $\mathrm{z}=$ $0.25, \mathrm{p}=0.805)$.

\section{Discussion}

In this work, I have analyzed gender differences in lying using a dataset of 8,728 distinct observations, collected using the sender-receiver game, in 65 experimental treatments, from 14 research groups. Following previous work and motivated by theoretical considerations, I have distinguished three types of lies: black lies, altruistic white lies, and Pareto white lies. The results show that: (i) males are significantly more likely than females to tell black lies; (ii) males are significantly more likely than females to tell altruistic white lies; (iii) results are inconclusive in the case of Pareto white lies. Furthermore, gender differences in telling altruistic white 


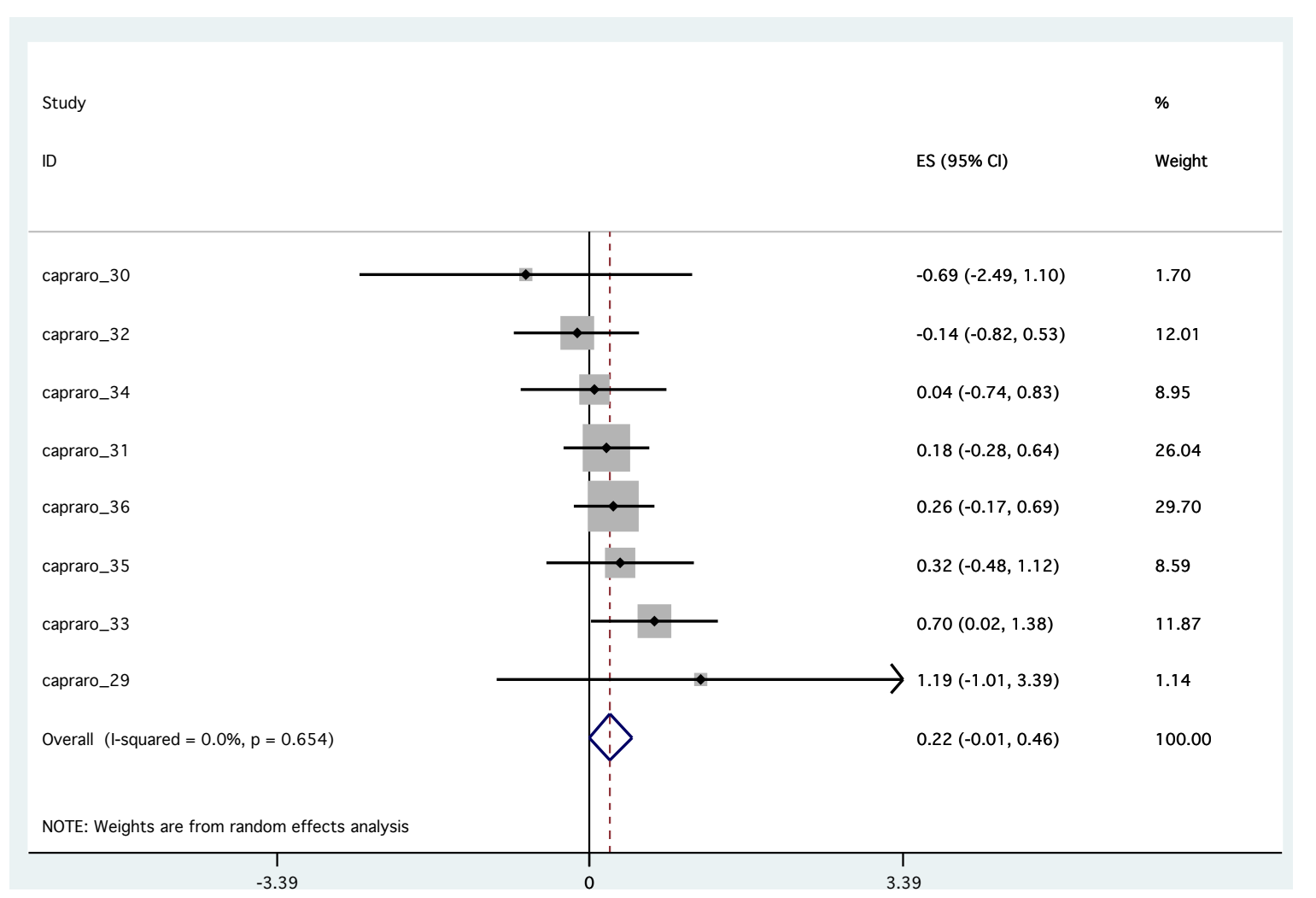

FIGURE 4: Forest plot of the meta-analysis of the gender differences in telling Pareto white lies (with no control on age and level of education).

lies are stronger than gender differences in telling black lies and stronger than gender differences in telling Pareto white lies. (The difference between black lies and Pareto white lies is not quite significant, but the gender effect size for Pareto lies is essentially the same as that for black lies, although the sample size of the former is smaller.)

To the best of my knowledge, this is the first meta-analysis on gender differences in lying, which also takes into account the consequences of lying. The closest work I am aware of is indeed a meta-analysis of empirical studies measuring (dis)honesty using the die-under-cup task (Abeler, Nosenzo $\&$ Raymond, in press). In the die-under-cup paradigm, subjects roll a die, privately, and then are paid according to the outcome they report. In this way subjects are incentivized to misreport the outcome (Fischbacher \& Föllmi-Heusi, 2013). Thus, among the black lie, the altruistic white lie, and the Pareto white lie conditions, the one that is nearer to the dieunder-cup task is the black lie condition: in both the black lie condition and the die-under-cup task the liar benefits from the lie and the lie harms someone else (although the negative effect of the lie on someone else is somewhat more salient in the sender-receiver game, where another player is directly harmed, than in the die-under-cup task, where the experimenter is indirectly harmed). In line with the current meta-study, also Abeler et al. (in press) finds that males are more likely than females to lie.

The main innovation of the current work is to consider also the consequences of lying. Taking them into account is crucial, especially in light of previous work on lying aversion, social preferences, and deontological moral judgments, which suggest that gender differences in lying may depend on the consequences of the lie. For example, Erat and Gneezy (2012) found that females are more dishonest than males in the case of altruistic white lies, while males may be more dishonest than females in the case of Pareto white lies.

In contrast to Erat and Gneezy (2012), the current metaanalysis shows that males are more dishonest than females also in the case of altruistic white lies. However, it is important to note that the current analysis does not include the data from Erat and Gneezy $(2012)^{5}$, showing the opposite effect. One may thus wonder whether including Erat and Gneezy (2012) might change the results. To address this

${ }^{5}$ I asked the data by email to Uri Gneezy, who replied that "the relevant data from my papers (gender and decisions) is in the papers or online appendix". Not having found the exact data on the appendix, I used the results reported in the paper to estimate the effect as reported in the main text. 
point, I have conducted a robustness check by estimating the logit regression coefficients in Erat and Gneezy (2012) from the results reported in their paper ${ }^{6}$. Re-running the metaanalysis by adding this estimated coefficient does not change the qualitative result: males still appear to lie significantly more than females (without control: effect size $=0.395,95 \%$ CI [0.158,0.632], $\mathrm{Z}=3.27, \mathrm{p}=0.001$; with control: effect size $=0.45095 \%$ CI $[0.221,0.680], Z=3.84, p<0.001)$. This suggests that the original finding by Erat and Gneezy (2012) might have been a false positive.

The current results are inconclusive in the case of Pareto white lies. Males seem to be slightly more dishonest than females, but the results fall short of statistical significance. Still, there might be a small effect that I was unable to detect due to the limited power. ${ }^{7}$ One might thus wonder whether the effect would become significant with a larger sample. As far as I know, there is only one paper using Pareto white lies that it is not included in this meta-analysis, and this is this work by Cappelen et al. (2013). ${ }^{8}$ Does including this study resolve this inconclusiveness? Unfortunately, this does not happen, fundamentally because the results are actually trending in the opposite direction, with females slightly more likely to lie than males. More formally, by estimating the coefficient from Cappelen et al. (2013) ${ }^{9}$ and rerunning the meta-analysis, I still find that males are not significantly more dishonest than females (without control: $95 \%$ CI [-0.079,0.328], $\mathrm{Z}=1.20, \mathrm{p}=0.231$; with control: $95 \%$ CI $[-0.092,0.322], \mathrm{Z}=1.09, \mathrm{p}=0.278)$. Note that the p-values are further away from significance, essentially because, as already mentioned, Cappelen et al.'s (2013) results are trending in the opposite direction from the original effect.

As described in the Theoretical Considerations section, the overall pattern of results is consistent with the hypothesis that females and males do not differ in the intrinsic cost of lying, but they differ only on social preferences: males are more selfish than females and more concerned about social efficiency than females; while females are more concerned than males about reaching an equitable distribution of payoffs. This explanation is consistent with the main effects of gender for each type of lie because all altruistic white lies conditions analyzed in this work are characterized by

${ }^{6}$ Erat and Gneezy (2012) conducted an altruistic white lie condition with $\mathrm{N}=101$ subjects (62 males and 39 females). Also in their experiment, lying is socially efficient while being honest is egalitarian. They found a proportion of lying of $41 \%$ among females and $27 \%$ among males. To estimate the logit regression coefficient, I assume that 16 females lie versus 17 males.

${ }^{7}$ Power analysis shows that to detect the overall effect with power 0.9 at a 5\% level one needs a sample of size $\mathrm{N}=2,103$.

${ }^{8}$ I emailed all three authors of the Cappelen et al. (2013) paper to ask for their data, but I received no answer. For this reason, I opted for estimating their effect from the result reported in their paper and included this in the present additional analysis.

${ }^{9}$ To estimate the regression coefficients, I use the results reported in Cappelen et al. (2013) as follows. Lying was $65.6 \%$ among females and $61.9 \%$ among males. I assume they have 200 males and 200 females, although in reality they have 352 subjects in total. the fact that lying increases the social welfare while being honest minimizes inequities. This explanation seems also consistent with the moderation effect of lie type: in all studies for which the payoff consequences of lying depend only on the sender's decision (that are only my studies), Pareto lies are more equitable than altruistic lies, and altruistic lies are on average more socially efficient than black lies. (The average increase in efficiency when telling altruistic lie is 9 cents, while the average increase in efficiency in telling black lies is only 4.91 cents).

Of course, more work should be devoted to test this hypothesis. For example, it would be important to explore gender differences in telling altruistic white lies in situations in which lying minimizes payoff differences, while being honest is socially efficient and maximize the individual payoff. The aforementioned view predicts that the sign of the gender difference in this case should switch.

Future research should also explore gender differences in telling spiteful lies, that is, lies that harm both players. Unfortunately, this kind of lie has been studied very little in the literature. The only study I am aware of is by Rosaz and Villeval (2012), who found only $3.9 \%$ of lying. They did not report gender differences. Exploring gender differences in the decision to tell spiteful lies is an interesting avenue for future research.

Another interesting route for further work regards finding potential moderators. The current analysis found no heterogeneity effect in the meta-analysis. Of course, this does not imply that the gender effect is not moderated by any variable. It could simply be that I was not able to detect heterogeneity because of insufficient power. Exploring whether the gender effect is moderated by other variables could be an interesting topic for further research.

In sum, here I studied gender differences in lying using a large dataset of 8,728 observations on the sender-receiver game. I found two clear results: males are more likely than females to tell black lies, and males are more likely than females to tell altruistic white lies (at least when lying is socially efficient). Future research should explore gender differences in the case of Pareto white lies and spiteful lies, and in the case of altruistic white lies, when lying minimizes payoff differences, while being honest is socially efficient and individually optimal.

\section{References}

Abeler, J., Nosenzo, D., \& Raymond, C. (in press). Preferences for truth-telling. Econometrica.

Andreoni, J., \& Vesterlund, L. (2001). Which is the fair sex? Gender differences in altruism. The Quarterly Journal of Economics, 116, 293-312.

Barcelo, H., \& Capraro, V. (2017). The Good, the Bad, and the Angry: An experimental study on the heterogene- 
ity of people's (dis)honest behavior. Available at SSRN: https://ssrn.com/abstract=3094305.

Biziou-van-Pol, L., Haenen, J., Novaro, A., OcchipintiLiberman, A., \& Capraro, V. (2015). Does telling white lies signal pro-social preferences? Judgment and Decision Making, 10, 538-548.

Brañas-Garza, P., Capraro, V., \& Rascón-Ramírez, E. (2018). Gender differences in altruism on Mechanical Turk: Expectations and actual behaviour. Economics Letters, 170, 19-23.

Byrnes, J. P., Miller, D. C., \& Schafer, W. D. (1999). Gender differences in risk taking: A meta-analysis. Psychological Bulletin, 125, 367-383.

Cappelen, A. W., Nygaard, K., Sørensen, E. Ø., \& Tungodden, B. (2015). Social preferences in the lab: A comparison of students and a representative population. The Scandinavian Journal of Economics, 117, 1306-1326.

Cappelen, A. W., Sørensen, E. Ø., \& Tungodden, B. (2013). When do we lie? Journal of Economic Behavior and Organization, 93 258-265.

Capraro, V. (2017). Does the truth come naturally? Time pressure increases honesty in one-shot deception games. Economics Letters, 158, 54-57.

Capraro, V., \& Peltola, N. (2018). Lack of deliberation drives honesty among men but not women. Available at SSRN: https://www.ssrn.com/abstract=3182830.

Capraro, V., \& Sippel, J. (2017). Gender differences in moral judgment and the evaluation of gender-specified moral agents. Cognitive Processing, 4, 399-405.

Capraro, V., Schulz, J., \& Rand, D. G. (2018). Time pressure increases honesty in a senderreceiver deception game. Available at SSRN: https://www.ssrn.com/abstract $=3184537$.

Carpenter, J., Connolly, C., \& Myers, C. K. (2008). Altruistic behavior in a representative dictator experiment. Experimental Economics, 11, 282-298.

Childs, J. (2012). Gender differences in lying. Economics Letters, 114, 147-149.

Cohen, T. R., Gunia, B. C., Kim-Jun, S. Y., \& Murnighan, J. K. (2009). Do groups lie more than individuals? Honesty and deception as a function of strategic self-interest. Journal of Experimental Social Psychology, 45, 1321-1324.

Cohen, T. R., Wolf, S. T., Panter, A. T., \& Insko, C. A. (2011). Introducing the GASP scale: A new measure of guilt and shame proneness. Journal of Personality and Social Psychology, 100, 947-966.

Conrads, J., Irlenbusch, B., Rilke, R. M., \& Walkowitz, G. (2013). Lying and team incentives. Journal of Economic Psychology, 34 1-7.

Croson, R., \& Gneezy, U. (2009). Gender differences in preferences. Journal of Economic Literature, 47, 448-474.

De Wit, A., \& Bekkers, R. (2016). Exploring gender differences in charitable giving: The Dutch case. Nonprofit and Voluntary Sector Quarterly, 45, 741-761.
Dreber, A., \& Johannesson, M. (2008). Gender differences in deception. Economics Letters, 99, 197-199.

Eagly, A. H. (1987). Sex differences in social behavior: A social-role interpretation. Mahwah, NJ: L. Erlbaum Associates.

Erat, S., \& Gneezy, U. (2012). White lies. Management Science, 58, 723-733.

Fischbacher, U., \& Föllmi-Heusi, F. (2013). Lies in disguise - An experimental study on cheating. Journal of the European Economic Association, 11, 525-547.

Fosgaard, T., Hansen, L. G., \& Piovesan, M. (2013). Separating will from grace: An experiment on conformity and awareness in cheating. Journal of Economic Behavior and Organization, 93, 279-284.

Friesen, L., \& Gangadharan, L. (2012). Individual level evidence of dishonesty and the gender effect. Economics Letters, 117 624-626.

Friesdorf, R., Conway, P., \& Gawronski, B. (2015). Gender differences in response to moral dilemmas: a process dissociation analysis. Personality and Social Psychology Bulletin, 41, 696-713.

Fumagalli, M., Ferrucci, R., Mameli, F., Marceglia, S., Mrakic-Sposta, S., Zago, S., Lucchiari, C., Consonni, D., Nordio, F., Pravettoni, G., Cappa, S., \& Priori, A. (2010). Gender-related differences in moral judgment. Cognitive Processing, 11, 219-226.

Gino, F., Ayal, S., \& Ariely, D. (2013). Self-serving altruism? The lure of unethical actions that benefit others. Journal of Economic Behavior and Organization, 93, 285-292.

Gino, F., Norton, M., \& Ariely, D. (2010). The counterfeit self: The deceptive costs of faking it. Psychological Science, 21 712-720.

Gino, F., Schweitzer, M. E., Mead, N. L., \& Ariely, D. (2011). Unable to resist temptation: How self-control depletion promotes unhetical behavior. Organizational Behavior and Human Decision Processes, 115, 191-203.

Gneezy, U. (2005). Deception: The role of consequences. The American Economic Review, 95, 285-292.

Gneezy, U., Kajackaite, A., \& Sobel, J. (2018). Lying aversion and the size of the lie. The American Economic Review, 108, 419-453.

Gneezy, U., Rockenbach, B., \& Serra-Garcia, M. (2013). Measuring lying aversion. Journal of Economic Behavior and Organization, 93 293-300.

Greenberg, A. E., Smeets, P., \& Zhurakhovska, L. (2015). Promoting truthful communication through ex-post disclosure. Available at SSRN: https://ssrn.com/abstract= 2544349.

Greene, J. D., \& Paxton, J. M. (2009). Patterns of neural activity associated with honest and dishonest moral decisions. Proceedings of the National Academy of Sciences, 106 12506-12511. 
Gunia, B. C., Wang, L., Huang, L., Wang, J. W., \& Murnighan, J. K. (2012). Contemplation and conversation: subtle influences on moral decision making. Academy of Management Journal, 55, 13-33.

Hershfiel, H. E., Cohen, T. R., \& Thomson, L. (2012). Short horizons and tempting situations: Lack of continuity to our future selves leads to unethical decision making and behavior. Organizational Behavior and Human Decision Processes, 117, 298-310.

Horton, J. J., Rand, D. G., \& Zeckhauser, R. J. (2011). The online laboratory: Conducting experiments in a real labor market. Experimental Economics, 14, 399-425.

Kocher, M. G., Pahlke, J., \& Trautmann, S. T. (2013). Tempus fugit: time pressure in risky decisions. Management Science, 59 2380-2391.

Kouchaki, M., Smith-Crowe, K., Brief, A. P., \& Sousa, C. (2013). Seeing green: Mere exposure to money triggers a business decision frame and unethical outcomes. Organizational Behavior and Human Decision Processes, 121, 53-61.

Kouchaki, M., \& Smith, H. I. (2014). The morning morality effect: The influence of time of day on unethical behavior. Psychological Science, 25, 95-102.

Levine, E. E., \& Schweitzer, M. (2014). Are liars ethical? On the tension between benevolence and honesty. Journal of Experimental Social Psychology, 53, 107-117.

Levine, E. E., \& Schweitzer, M. (2015). Prosocial lies: When deception breeds trust. Organizational Behavior and Human Decision Processes, 26, 88-106.

Lohse, T., Simon, S. A., \& Konrad, K. A. (2018). Deception under time pressure: Conscious decision or a problem of awareness. Journal of Economic Behavior and Organization, 146, 31-42.

Mazar, N., Amir, O., \& Ariely, D. (2008). The dishonesty of honest people: A theory of self-concept maintenance. Journal of Marketing Research, 45, 633-644.

Mesch, D. J., Rooney, P. M., Steinberg, K. S., \& Denton, B. (2006). The effects of race, gender, and marital status on giving and volunteering in Indiana. Nonprofit and Voluntary Sector Quarterly, 35, 565-587.

Niederle, M., \& Vesterlund, L. (2007). Do women shy away from competition? Do men compete too much? The Quarterly Journal of Economics, 122, 1067-1101.

Paolacci, G., Chandler, J., \& Ipeirotis, P. G. (2010). Running experiments on Amazon Mechanical Turk. Judgment and Decision Making, 5, 411-419.

Paolacci, G., \& Chandler, J. (2014). Inside the Turk: Understanding Mechanical Turk as a participant pool. Current Directions in Psychological Science, 23, 184-188.
Pascual-Ezama, D., Prelec, D., \& Dunfield, D. (2013). Motivation, money, prestige, and cheats. Journal of Economic Behavior and Organization, 93, 367-373.

Piper, G., \& Schnepf, S. V. (2008). Gender differences in charitable giving in Great Britain. Voluntas, 19, 103-124.

Ploner, M., \& Regner, T. (2013). Self-image and moral balancing: An experimental analysis. Journal of Economic Behavior and Organization, 93, 374-383.

Rand, D. G., Brescoll, V. L., Everett, J. A. C., Capraro, V., \& Barcelo, H. (2016). Social heuristics and social roles: Intuition favors altruism for women, but not for men. Journal of Experimental Psychology: General, 145, 389-396.

Rode, J. (2010). Truth and trust in communication: Experiments on the effect of a competitive context. Games and Economic Behavior, 68, 325-338.

Roeser, K., McGregor, V. E., Stegmaier, S., Mathew, J., Kübler, A., \& Meule, A. (2016). The Dark Triad of personality and unethical behavior at different times of day. Personality and Individual Differences, 88, 73-77.

Rosaz, J., \& Villeval, M. C. (2012). Lies and biased evaluation: A real-effort experiment. Journal of Economic Behavior and Organization, 84, 537-539.

Shalvi, S., \& de Dreu, C. K. W. (2014). Oxytocin promotes group-serving dishonesty. Proceedings of the National Academy of Sciences USA, 111, 5503-5507.

Shalvi, S., Eldar, O., \& Bereby-Meyer, Y. (2012). Honesty requires time (and lack of justification). Psychological Science, 23, 1264-1270.

Shalvi, S., \& Leiser, D. (2013). Moral firmness. Journal of Economic Behavior and Organization, 93, 400-407.

Sheremeta, R. M., \& Shields, T. W. (2013). Do liars believe? Beliefs and other-regarding preferences in sender-receiver games. Journal of Economic Behavior and Organization, 94, 268-277.

Sutter, M. (2009). Deception through telling the truth? Experimental evidence from individuals and teams. Economic Journal, 11947-60.

van't Veer, A. E., Stel, M., \& van Beest, I. (2014). Limited capacity to lie: Cognitive load interferes with being dishonest. Judgment and Decision Making, 9, 199-206.

Weisel, O., \& Shalvi, S. (2015). The collaborative roots of corruption. Proceedings of the National Academy of Sciences, 112 10651-10656.

Wiltermuth, S. S. (2011). Cheating more when the spoils are split. Organizational Behavior and Human Decision Processes, 115 157-168. 